\title{
EVENTOS DE VIDA E ESTRATÉGIAS DE COPING DE IDOSOS SOCIALMENTE ATIVOS ${ }^{1}$
}

\author{
Josiane Lieberknecht Wathier ${ }^{2}$ \\ Fernanda Wilhelm ${ }^{3}$ \\ Claudia Hofheinz Giacomoni ${ }^{4}$ \\ Débora Dalbosco Dell'Aglio ${ }^{5}$
}

\section{Resumo}

Este estudo verificou eventos de vida estressantes de uma amostra de idosos socialmente ativos $(\mathrm{N}=40 ; \mathrm{M}=70,40$ anos; $\mathrm{DP}=6,24)$. Além disso, procurou-se identificar os tipos de estratégias de coping utilizadas para lidar com esses eventos relacionados à vida em geral. Para tanto, utilizouse uma entrevista semi-estruturada e que posteriormente foi submetida à análise de conteúdo. Os resultados mostraram que os eventos negativos versaram principalmente sobre doença, morte e perdas. A estratégia de $\mathrm{Co}-$ ping mais utilizada frente aos eventos estressantes da vida foi "Ação Direta". Pode-se considerar que esses idosos utilizaram seu repertório prévio adquirido com sua experiência de vida para empregar estratégias adaptadas para a ação. Possivelmente esses resultados estão ligados aos fatores que influenciam o envelhecimento bem-sucedido encontrados na literatura, uma vez que os participantes eram socialmente ativos.

Palavras-Chave: Idosos. Eventos de Vida. Estratégias de Coping.

\footnotetext{
${ }^{1}$ Este artigo foi escrito a partir da Monografia de Conclusão de Graduação da primeira autora, cuja pesquisa foi desenvolvida junto ao Laboratório de Estudos, Medidas e Avaliação em Psicologia (LEMAP) da Universidade Federal de Santa Maria (UFSM) com apoio financeiro da Fundação de Amparo à Pesquisa do Rio Grande do Sul (FAPERGS). Agradecemos aos demais acadêmicos de psicologia da UFSM vinculados ao LEMAP pelo auxílio na coleta e levantamento dos dados, bem como aos idosos que se dispuseram a participar deste estudo.

${ }^{2}$ Psicóloga. Mestranda do Curso de Pós-Graduação em Psicologia do Desenvolvimento da Universidade Federal do Rio Grande do Sul (UFRGS).

${ }^{3}$ Acadêmica do Curso de Psicologia da Universidade Federal de Santa Maria (UFSM).

${ }^{4}$ Psicóloga. Doutora pelo Curso de Pós-Graduação em Psicologia do Desenvolvimento da UFRGS. Professora do Curso de Psicologia da UFSM.

${ }^{5}$ Psicóloga, doutora pelo Curso de Pós-Graduação em Psicologia do Desenvolvimento da UFRGS e professora do Programa de Pós-graduação em Psicologia do Desenvolvimento do Instituto de Psico-logia da UFRGS. E-mail: josianelieb@yahoo.com.br
} 


\section{Introdução}

A ciência do envelhecimento costuma enfrentar inúmeros desafios, como a influência das estruturas econômicas, culturais, sociais e emocionais no processo de envelhecer. Estudar quais os eventos de vida estressantes são mais citados por idosos e a repercussão desses na sua vida e na das pessoas que o cercam é uma grande preocupação científica (YASSUDA; NERI; CACHIONI, 2004). Além disso, tem havido uma grande busca sobre quais estilos de vida levam à longevidade (ARGIMON, 2002). Nesse sentido, o presente estudo buscou investigar eventos de vida estressantes e estratégias de coping em idosos com estilo de vida socialmente ativo.

Numa pesquisa realizada recentemente (MORAES; SOUZA, 2005), encontraram fatores que possivelmente influenciam o envelhecimento bem-sucedido de idosos socialmente ativos, como relações familiares e de amizade, saúde e bem-estar percebido, capacidade funcional, e suporte psicossocial. Tal conjunto de fatores está relacionado a idosos que levam uma vida socialmente ativa, ou seja, participam de grupos de convivência ou exercem alguma atividade fora da nucleação familiar.

\section{Eventos de Vida}

Eventos de vida são acontecimentos significativos que ocorrem entre um ponto e outro relativamente estável na vida de um indivíduo (FORTES; NERI, 2004). Ao experimentar um evento de vida negativo, o indivíduo precisará utilizar seus recursos emocionais, sociais e intelectuais num grau que está relacionado a maior ou menor valorização a isso atribuída. Além da avaliação feita pelo indivíduo, a origem (interna ou externa), biológica, psicológica ou social, o grau de previsibilidade, a duração dos recursos de apoio, e o grau de controle sobre a situação são variáveis que influenciam o quão estressante pode ser o evento. Além do mais, sabe-se que os eventos positivos também demandam que a pessoa se ajuste a eles, podendo ser algo igualmente estressante (ALDWIN, 1994).

O paradigma do desenvolvimento ao longo do curso de vida (lifespan) diferencia eventos normativos de não-normativos, que são, respectivamente, os esperados e os não-esperados. Nesse modelo, apresentado por Baltes (1987), os eventos normativos podem ser graduados por idade ou por história, sendo que os primeiros têm uma época esperada para acon- 
tecer, como a queda dos dentes de leite e a menopausa, por exemplo, e os outros são esperados num contexto social (como entrar na escola, casarse ou aposentar-se). Esses eventos possuem alto grau de controlabilidade, já que se pode prever seu acontecimento durante o desenvolvimento. Já os eventos idiossincráticos ou não-normativos podem representar uma ameaça ao senso de controle individual, dada sua imprevisibilidade. Nessa dimensão, vale reafirmar que tanto ganhar na loteria (evento positivo) quanto sofrer um acidente de automóvel (evento negativo) exige grande esforço de adaptação para restabelecer o curso normal de desenvolvimento (FORTES; NERI, 2004).

Os eventos relacionados com a saúde podem surgir com mais freqüência na etapa de desenvolvimento da velhice do que nos outros períodos da vida, conforme Bee (1997) e Beckett et al. (2002). Outro estudo afirmou que doenças da velhice que restringem os movimentos, por exemplo, exigem uma adaptação frente às novas funções biológicas (restrições dos movimentos) e aos novos papéis sociais (ser um inválido), o que pode ser muito penoso para o velho e seus cuidadores (FORTES; NERI, 2004).

Em um estudo com 544 idosos que alegaram ter vivido eventos estressantes nos últimos cinco anos, Fortes (2005) encontrou cinco categorias de eventos de vida: eventos relacionados à finitude; à incontrolabilidade; ao cuidado; se pontuais ou de crise; e relacionados ao bem-estar psicológico. Frente a esses eventos, a autora identificou cinco fatores de estratégias de enfrentamento (coletados a partir de uma adaptação do Inventário de Estratégias de Coping da Califórnia - 19 itens). As estratégias foram: expressão de emoções negativas; controle ambiental; religiosidade; comportamento de esquiva; e inibição das emoções. Comparando as estratégias de coping utilizadas com o risco de depressão, a autora encontrou pontos em comum. O risco de depressão, na sua amostra, estava associado aos seguintes fatores: uso de estratégias de enfrentamento com foco na expressão de emoções negativas; experiências de eventos incontroláveis; ter entre 60 e 69 anos; e avaliar sua auto-eficácia no enfrentamento como inadequada.

A grande relevância dos eventos negativos e positivos e dos fatores relacionados a esses para a qualidade de vida dos idosos ressalta a heterogeneidade do envelhecer humano. Na maioria dos estudos relacionados com terceira idade, essas variáveis têm sido focalizadas na doença em detrimento dos aspectos positivos adquiridos com o envelhecer. 


\section{Estratégias de Coping}

Quando alguém está diante de um evento estressante e busca uma ação para lidar com a situação, ela utilizou uma estratégia de coping. Utiliza-se a palavra coping, do verbo to cope, em inglês, por esta não ter uma tradução adequada para o português. A idéia que mais se aproxima é a de "enfrentamento". Há muitas definições sobre o processo de coping (ANTONIAZZI; DELL'AGLIO; BANDEIRA, 1998). Neste estudo utilizarse-á a definição de Lazarus e Folkman (1984), segundo os quais coping é um conjunto de esforços cognitivos e comportamentais, utilizado pelos indivíduos com o objetivo de lidar com demandas específicas, internas ou externas, que surgem em situações de estresse e são avaliadas como sobrecarregando ou excedendo seus recursos pessoais.

De acordo com Fortes e Neri (2004), a adaptação frente a uma situação estressante depende da noção do que é funcional para a pessoa, ou seja, da forma como cada um avalia a situação vivida. Diante de eventos incontroláveis como a morte de um filho e a perda de todos os bens materiais num acidente ecológico, a aceitação pode ser a única forma encontrada por um indivíduo para se manter bem emocionalmente.

Vale ressaltar que o coping tem a função de administração da situação estressora e não o controle ou o domínio da mesma. Também é importante perceber que a situação estressante está sempre mudando e, por isso, o processo de coping é dinâmico e está em constante desenvolvimento. Sendo assim, o ajuste da pessoa a uma situação pode permanecer estável ou mudar no decorrer do tempo. Conforme o modelo de avaliação cognitiva para coping esquematizado por Lazarus e Folkman (1984), o indivíduo avalia a situação, os recursos pessoais e as pressões ambientais. Em seguida, a pessoa escolhe e aplica uma estratégia de coping. Caso tenha funcionado, essa estratégia será mantida e utilizada em situações futuras semelhantes. Porém, se não funcionar, será necessária uma reavaliação da situação estressante e implementação de outra estratégia.

Há que se ressalvar, entretanto, que a definição do conceito de estresse ainda não é consensual entre os teóricos da área (SKINNER, 1995). Aldwin (1994) definiu estresse como sendo uma qualidade de experiência que se dá por superativação ou rebaixamento do nível de alerta produzida por interação entre o indivíduo e o ambiente e que resulta em desconforto psicológico ou fisiológico. Nessa perspectiva interacionista, expressar 
reações como medo, culpa e vergonha caracteriza estados emocionais de estresse tanto quanto a expressão de emoções positivas, tais como alegria, felicidade e alívio. Para o presente estudo, o estresse está sendo considerado como algo subjetivo que ultrapassa a capacidade do indivíduo de lidar com a situação, desequilibrando seu bem-estar.

Beresford (1994) alerta que a estratégia de enfrentamento deve ser vista independentemente do resultado. Qualquer tentativa de administrar o estressor é considerada coping. O próprio envelhecimento, por sua vez, pode ser considerado um fator de estresse, visto que há uma grande tendência das pessoas dessa faixa etária em manter vínculos de dependência em que têm sua autonomia diminuída, conforme destaca Kroeff (2001). Somam-se a isso, as doenças, as perdas de papéis ocupacionais e as perdas afetivas que apresentam maior chance de ocorrer com idosos, ocasionando diferentes graus de ansiedade, dependendo da história e das condições estruturais de cada um (HAMARAT et al., 2002).

Igualmente, Neri (1993) aponta que as pesquisas sobre envelhecimento buscam a investigação dos mecanismos compensatórios e adaptativos que podem permitir envelhecer bem, o que ajuda a estabelecer novos limites à plasticidade do organismo humano. Papalia e Olds (2000) acrescentam que, com a idade, as pessoas desenvolvem um repertório mais flexível de estratégias de coping. Pessoas mais velhas podem estar mais capazes do que pessoas mais jovens para usar a regulação de emoções quando uma situação parece exigi-la.

Quanto à adequação do instrumento para medir coping, Seidl, Troccoli e Zannon (2001) relataram tentativas de vários autores em diferentes países em construir um instrumento capaz de detectar e mensurar estratégias de enfrentamento, mas nenhum é considerado suficientemente adequado. Antoniazzi, Dell'Aglio e Bandeira (1998) encontraram referências de que a entrevista semi-estruturada ainda é o método mais adequado para avaliar coping, uma vez que preserva as diferenças na forma de refletir, recordar e relatar como a pessoa lida com situações de estresse.

Independentemente do instrumento utilizado para identificar essas estratégias, é importante destacar que vários estudos encontraram resultados semelhantes sobre quais estratégias de coping correlacionam-se de forma consistente com bem-estar subjetivo. Entre essas: crenças espirituais, dar significado positivo aos eventos, reavaliações positivas, coping focado no problema (HEADEY; WEARING, 1989; FOLKMAN, 1997). 
Também McCrae e Costa (1986) encontraram que pessoas com altos níveis de bem-estar relataram o uso das seguintes estratégias de coping: ação racional, procurar ajuda, extrair força da adversidade e fé.

Dessa forma, o presente estudo buscou investigar quais os eventos de vida estressantes são citados pelos idosos socialmente ativos e as estratégias de coping utilizadas frente a esses problemas. Partiu-se do pressuposto de que idosos socialmente ativos possuem melhor qualidade de vida, apesar de sofrerem situações semelhantes às enfrentadas por outros grupos de idosos. Pretendeu-se identificar as estratégias mais utilizadas frente aos eventos, o que poderá contribuir para estudos futuros sobre a construção de modelos de aprendizagem de estratégias mais eficazes entre os idosos de qualidade de vida mais baixa.

\section{Método}

O presente estudo teve delineamento qualitativo e quantitativo. A seguir, são apresentados os participantes, os instrumentos e procedimentos adotados, bem como as considerações éticas seguidas.

\subsection{Participantes}

Participaram desse estudo 40 idosos socialmente ativos (freqüentadores de grupos da terceira idade ou de outras atividades fora do núcleo familiar) da cidade de Santa Maria, que tinham idade acima de 60 anos e que não apresentaram dificuldade em responder às perguntas da entrevista. A média de idade dos participantes foi de 70,4 anos $(\mathrm{DP}=6,24)$, sendo 22 mulheres (55\%) e 18 homens (45\%).

As características sociodemográficas dos idosos foram analisadas focalizando as variáveis sexo, idade, escolaridade, estado civil e participação de grupos. Como se pode ver na Tabela 1, pouco mais da metade da amostra feminina possuía entre 60 e 69 anos. Já entre os participantes do sexo masculino houve predominância da faixa de idade entre 70 a 79 anos.

Considerando o estado civil, $62,50 \%$ dos participantes da amostra eram casados (incluindo formas de união estável e segundo ou terceiro casamentos), sendo que uma minoria era solteira ou separada. Em relação aos anos de escolaridade, observou-se que quase $50 \%$ dos idosos entrevis- 
tados completaram segundo grau e/ou seguiram no ensino superior (ver Tabela 1).

Tabela 1- Distribuição e Percentual dos Idosos Conforme Escolaridade, Estado Civil, Sexo e Faixa Etária ( $\mathrm{N}=40)$

\begin{tabular}{|c|c|c|c|c|}
\hline \multicolumn{3}{|c|}{ Variável } & $\mathbf{n}$ & $\%$ \\
\hline \multirow{4}{*}{ Escolaridade } & \multicolumn{2}{|c|}{ Superior ou mais } & 11 & 27,50 \\
\hline & \multicolumn{2}{|c|}{ De 7 a 16 anos de escola } & 13 & 32,50 \\
\hline & \multicolumn{2}{|c|}{ De 4 a 6 anos de escola } & 6 & 15,00 \\
\hline & \multicolumn{2}{|c|}{ Até 3 anos de escola } & 10 & 25,00 \\
\hline \multirow{4}{*}{ Estado Civil } & \multicolumn{2}{|c|}{ Casado } & 25 & 62,50 \\
\hline & \multicolumn{2}{|l|}{ Viúvo } & 10 & 25,00 \\
\hline & \multicolumn{2}{|l|}{ Separado } & 2 & 5,00 \\
\hline & \multicolumn{2}{|l|}{ Solteiro } & 3 & 7,50 \\
\hline \multirow{6}{*}{ Faixa Etária } & \multirow{3}{*}{ Mulheres } & $60-69$ anos & 12 & 54,40 \\
\hline & & 70-79 anos & 7 & 31,81 \\
\hline & & $80-85$ anos & 3 & 13,63 \\
\hline & \multirow{3}{*}{ Homens } & $60-69$ anos & 8 & 44,40 \\
\hline & & 70-79 anos & 9 & 50,00 \\
\hline & & $80-85$ anos & 1 & 5,55 \\
\hline
\end{tabular}

Fonte: Dados obtidos na pesquisa.

Dois participantes desse estudo não freqüentavam nenhum tipo de grupo de terceira idade, mas exerciam atividades fora do núcleo familiar, como trabalhar, ir ao banco, ao bingo, entre outras. O restante participava de um ou mais grupos ou de atividades sociais que oferecem principalmente atividade física, além da convivência com pessoas de sua idade fora do núcleo familiar. Com base nesses dados, podemos inferir que os grupos mais freqüentados possuíam foco em Atividades Físicas e de Convivência $(58,3 \%)$, sendo seguidos de forma decrescente por Ação Social $(25,0 \%)$ e Oração $(16,6 \%)$.

\subsection{Instrumentos}

Foi utilizada uma entrevista semi-estruturada para coletar dados sociodemográficos, eventos de vida e estratégias de coping, composta por 
duas questões. Esse instrumento foi adaptado para idosos a partir do modelo de entrevista proposto por Dell'Aglio (2000) na sua tese de doutorado. Assim, pedíamos que o participante contasse uma situação difícil que tivesse acontecido recentemente em sua vida, com a finalidade de identificar um evento estressor. Na pergunta seguinte, era solicitado que ele descrevesse o que fez no momento em que tal situação difícil ocorreu, visando a identificar a estratégia utilizada.

\subsection{Procedimentos e Considerações Éticas}

Inicialmente foi obtida uma listagem dos grupos de terceira idade vinculados ao Núcleo Integrado de Estudo e Apoio à Terceira Idade (NIEATI), do Centro de Educação Física da Universidade Federal de Santa Maria (UFSM), com a finalidade de mapear os idosos socialmente ativos na cidade. Em seguida, começou-se a contatar alguns desses grupos localizados nos bairros com maior concentração de população idosa em Santa Maria. Nesse primeiro encontro, os idosos eram informados sobre os procedimentos do estudo e seus objetivos, deixando claro o caráter voluntário de participação na pesquisa e a realização da entrevista somente diante do consentimento do participante. Foram visitados oito grupos de terceira idade de Santa Maria, sendo que foram convidados, de forma coletiva, cerca de 80 idosos presentes no momento das visitas aos grupos.

Os participantes foram selecionados por conveniência de acordo com os seguintes critérios de inclusão: ser idoso socialmente ativo (participante de grupos da terceira idade ou de outras atividades fora do núcleo familiar), ser residente em Santa Maria, RS, ter idade acima de 60 anos (conforme Estatuto do Idoso), bem como não apresentar dificuldade em responder aos instrumentos. Foram excluídos deste estudo os idosos que não preenchiam os critérios de inclusão.

Quarenta e dois idosos se interessaram em participar do estudo e forneceram o número de telefone e endereço para marcar entrevista posterior ou responderam aos instrumentos no mesmo dia da visita, em local resguardado para esse fim. Apenas duas dessas entrevistas não puderam ser utilizadas nesse estudo devido a dificuldades apresentadas pelos participantes para entender as perguntas da entrevista. Todas as entrevistas foram gravadas em fita cassete e posteriormente transcritas na íntegra. As transcrições das entrevistas foram armazenadas no banco de dados da pes- 
quisadora responsável, junto ao Laboratório de Estudos, Medidas e Avaliação em Psicologia (LEMAP).

Os participantes da pesquisa foram informados dos objetivos da pesquisa e dos procedimentos a serem tomados. Foi lido em voz alta $\mathrm{o}$ Termo de Consentimento Livre e Esclarecido e, depois de dirimidas as dúvidas, entregue uma cópia para o participante, no caso de haver aceitado participar da pesquisa. Foi garantido o caráter voluntário da participação, bem como o respeito aos preceitos éticos que regem a realização de pesquisas com seres humanos (BRASIL, 1996). Conforme recomenda a Resolução do Conselho Federal de Psicologia (BRASIL, 2000), esse trabalho caracterizou-se por ser de risco mínimo aos participantes. Mesmo assim, tomou-se a precaução de observar o estado emocional da pessoa ao final da entrevista, permanecendo junto à mesma por mais alguns minutos. Não foi necessário encaminhar nenhum dos participantes para apoio psicológico.

\section{Resultados}

Através da análise de conteúdo das entrevistas (BARDIN, 1977), foram estabelecidas categorias para classificação dos eventos estressores e das estratégias de coping apresentadas. Para que não se perdesse a qualidade dos itens, foram considerados mais de um item de resposta por entrevistado em relação às estratégias. As respostas foram classificadas e foi observada a concordância entre juízes, que foi de $86,20 \%$ para os eventos e 79,01\% para as estratégias de coping.

Os eventos da vida estressantes levantados permitiram conhecer melhor as dificuldades recentes destacadas pelos participantes. A seguir são apresentadas as categorias de eventos utilizadas, e na Tabela 2 podem ser observadas as freqüências e percentuais dos eventos estressores citados:

a) morte/doença na família: refere-se à doença ou morte de alguém da família. Exclui respostas sobre doenças próprias, para as quais há uma categoria exclusiva. Exemplos: "morte do neto"; "filha viciada"; "doença do meu marido";

b) doença própria: refere-se à eleição de uma doença sua como situação estressante. Exemplos: "duas cirurgias que fiz"; "ter baixado a primeira vez no hospital"; "probleminha de saúde";

c) problemas com membros da família: inclui itens de resposta ligados 
ao relacionamento dos membros da família ou com eles, excetuandose morte ou doença. Exemplos: "viagem do filho para Maranhão"; "volta do filho (revoltado) pra casa";

d) problemas materiais: inclui itens que mencionam dificuldades financeiras ou violência sofrida em função de bens materiais. Exemplos: "dívida com camioneta"; "minha casa";

e) outros: refere-se a itens que não se encaixam nas categorias anteriores. Exemplos: "ameaça de roubo"; "parar de trabalhar".

Tabela 2 - Freqüência e Percentual dos Eventos Estressores por Categoria

\begin{tabular}{l|r|r}
\hline Categorias & F & \% \\
\hline 1. Morte / Doença na Família & 17 & 42,50 \\
\hline 2. Doença Própria & 8 & 20,00 \\
\hline 3. Problemas com membros da família & 7 & 17,50 \\
\hline 4. Problemas Materiais & 5 & 12,50 \\
\hline 5. Outros & 3 & 7,50 \\
\hline Total & $\mathbf{4 0}$ & $\mathbf{1 0 0 , 0 0}$ \\
\hline
\end{tabular}

Fonte: Dados obtidos na pesquisa.

Para compreendermos quais estratégias de coping que os participantes desse estudo utilizaram para enfrentar situações estressantes foi feita a pergunta "O que você fez no momento em que essa situação difícil ocorreu?".

A seguir são apresentadas as categorias de classificação das respostas, referentes às estratégias de coping, bem como a Tabela 3 , com as freqüências e percentuais destas estratégias:

a) ação direta: refere-se a um comportamento, por iniciativa própria, que elimine o estressor ou modifique suas características. Lida diretamente com o estressor. Exemplos: "chamei atendimento médico"; "procurei reagir"; "ajudei";

b) busca de apoio social: envolve respostas em que o indivíduo recorre, de forma não-agressiva, a alguma(s) pessoa(s) ou entidade(s) para solicitar auxílio para lidar com a situação estressante ou se sentir melhor frente a ela, sem o qual não tomaria iniciativa. Engloba pedidos a outros para que resolvam sua situação, incluindo apoio espiritual. Exemplos: "fomos na delegacia do idoso"; "vou em busca de outros"; "me agarrei na minha fé"; 
c) aceitação: refere-se aos itens de resposta que demonstram submissão à situação no sentido de aceitar a circunstância ou suportá-la. Exemplos: "eu agüentei"; "quando chega a hora da gente não adianta"; "eu aceitei";

d) expressão emocional: refere-se aos itens em que aparece manifestação de emoções e sentimentos ou enfatizam o controle dos mesmos. Exemplos: "eu me irrito"; "eu não tô contente"; "eu me fechei";

e) ação agressiva: inclui ações físicas ou verbais com a finalidade de afastar o estressor. Engloba respostas como manifestação de raiva, atitudes descontroladas, uso de violência física ou verbal, brigas, ou, ainda, coação. Exemplos: "xinguei ele"; "dei um empurrão nele";

f) inação: estratégia na qual o indivíduo não apresenta ação frente à situação estressante. Engloba respostas como não fazer nada, ficar parado, bloquear-se, não tomar iniciativa nenhuma. Exemplos: "quem ativou tudo foi os filhos"; "a gente fica meio parado";

g) outros: refere-se aos itens de resposta que não se encaixam nas categorias anteriores. Exemplos: "a gente não admite"; "perdia o sono".

Tabela 3 - Freqüência e Percentual das Estratégias de Coping Utilizadas

\begin{tabular}{l|r|r}
\hline Categorias & $\mathbf{F}$ & $\mathbf{\%}$ \\
\hline 1. Ação Direta & 53 & 54,08 \\
\hline 2. Busca de Apoio Social & 17 & 17,35 \\
\hline 3. Aceitação & 13 & 13,27 \\
\hline 4. Expressão Emocional & 7 & 7,14 \\
\hline 5. Ação Agressiva & 4 & 4,08 \\
\hline 6. Inação & 3 & 3,06 \\
\hline 7. Outros & 1 & 1,02 \\
\hline Total & $\mathbf{9 8}$ & $\mathbf{1 0 0 , 0 0}$ \\
\hline
\end{tabular}

Fonte: Dados obtidos na pesquisa.

\section{Discussão e Considerações Finais}

Esse estudo permitiu verificar os eventos estressores em uma amostra de idosos socialmente ativos e as estratégias de coping utilizadas para enfrentar tais situações. Com relação aos eventos de vida relatados como estressantes, foi possível verificar que os idosos da amostra têm enfrentado 
situações difíceis como morte dos pais, cônjuges e outros parentes além de doenças graves que lhes acometem ou afetam pessoas próximas. Todos esses eventos são pertinentes à etapa evolutiva da terceira idade, conforme encontrado na literatura sobre Psicologia do Desenvolvimento (BEE, 1997; FORTES; NERI, 2004; PAPALIA; OLDS, 2000). Outras autoras encontraram, em um estudo com idosos pertencentes à família de baixa renda, que envelhecer está associado a dificuldades econômicas, doenças e sentimentos de desvalorização social (SILVA; GÜINTER, 2000).

A tabela (2) das categorias de eventos estressores mostrou que questões sobre sentir-se sozinho, envelhecer e retornar ao passado ficam em segundo plano, ao passo que a morte do cônjuge ou de familiares, bem como doença própria ou de pessoas queridas sobressaem-se na eleição. No estudo de Fortes (2005), mais da metade dos idosos consideraram como o evento mais recente e estressante os problemas de saúde deles mesmos ou de pessoas próximas, e a morte de entes queridos, situações que remetem o indivíduo à experiência real ou imaginária da própria finitude. Outros estudos sobre idosos também encontraram resultados semelhantes (FORTES; NERI, 2004; ROKACH; AGE NETO, 2006).

Quanto ao enfrentamento dos referidos eventos, que foi predominantemente de ação direta, percebe-se que, mesmo que a terceira idade ofereça situações com as quais o idoso em geral ainda não lidou, ele consegue agir diretamente sobre o fator estressante. Pode-se pensar que, para essa amostra, as estratégias que funcionaram em situações anteriores, análogas quanto ao estresse, foram utilizadas como base. Alguns autores chamam esse fenômeno de processo de imunização (RAEDT; PONJAERT, 2006).

Espera-se que o indivíduo desenvolva habilidades para lidar com problemas pela experiência que vai sendo adquirida e pelo desenvolvimento geral (PAPALIA; OLDS, 2000). Por outro lado, no envelhecimento, há uma leve perda cognitiva e situações novas que precisam ser aprendidas para desenvolver estratégias, principalmente diante do caráter incontrolável desses eventos (PAPALIA; OLDS, 2000). Mas as perdas cognitivas que ocorrem na velhice, conforme Baltes (1987), podem ser compensadas por ganhos no domínio da inteligência prática.

Além disso, é necessário considerar a cultura em que o idoso está inserido, pois algumas pesquisas mostraram que a forma de idosos canadenses lidarem com problemas como a solidão é muito mais introspectiva do que para portugueses, por exemplo, como mostraram Rokach e Age 
Neto (2006). Pode-se inferir, dessa forma, que talvez os idosos da amostra brasileira tenham apresentado estratégias de coping mais ativas por estarem inseridos numa cultura onde a rede de apoio social é amplamente incentivada e possivelmente mais calorosa. Acrescenta-se a isso que os participantes dessa amostra eram idosos socialmente ativos, o que possivelmente ampliou sua rede de apoio social e seu nível de bem-estar geral. Também no estudo de Silva e Güinter (2000) os idosos continuaram a manter uma rede de amigos, mesmo que alguns ficassem mais restritos à família, o que facilita o ajustamento social na velhice, conforme as autoras.

Cabe discutir que, entre os idosos que permanecem socialmente ativos na velhice, existe um predomínio dos que ainda possuem um companheiro. Além disso, 52,50\% dos participantes tinham até oito anos de escolarização. Essas características vêm ao encontro de pesquisas que apontam a escolaridade mais alta, a rede de apoio social e afetiva e não ser viúvo como indicativos de um maior bem-estar na velhice (CACHIONI, 1998; NERI, 2001). A respeito dos papéis sociais na velhice, Silva e Güinter (2000) constataram em seu estudo que os idosos que tinham uma escolaridade maior possuíam uma rede de relações mais ampla.

As estratégias de busca de apoio e de aceitação, que ficaram em segundo e terceiro planos, podem ser compreendidas sob a questão óptica da incontrolabilidade. Diante de um evento como morte ou doença grave, que estão fora do controle dos idosos, aceitar e buscar apoio podem ser estratégias melhor adaptadas (DELL'AGLIO, 2000; FORTES; NERI, 2004). Na mesma direção, Rabelo e Neri (2005) identificaram que as ilusões positivas ajudam os indivíduos mais velhos a significar sua experiência, e que esses tendem a organizar seu ambiente de modo a maximizar os afetos positivos e minorar os negativos diante de alguma perda. Esse processo foi chamado pelas autoras de "otimização afetiva" . Ao citar Taylor, Kemeny, Reed, Bower, Grunewald, Rabelo e Neri (2005), destacam também que o otimismo irreal e a percepção exagerada de controle pessoal podem ser fatores psicológicos protetivos, podendo influenciar até mesmo sobre a evolução de uma doença física.

Este trabalho permitiu conhecer um pouco mais das facetas do envelhecimento dos idosos socialmente ativos, bem como as dificuldades e o enfrentamento das situações. Sabe-se que, apesar da existência de políticas públicas de atenção à terceira idade, essas não garantem ao idoso uma qualidade satisfatória de cuidados com sua saúde (SILVA; GÜINTER, 2000; 
SANTOS JÚNIOR, 2005). Os resultados do presente estudo podem contribuir para que se foquem ações de fortalecimento de estratégias nas intervenções com idosos, diante da imposição de limites da idade madura.

É necessário ressalvar, entretanto, que os resultados desse estudo estiveram condicionados a uma amostra pequena e a uma metodologia transversal. Mesmo assim, apontam a necessidade da continuação de estudos sobre estratégias de coping em pessoas idosas, especialmente através de metodologia longitudinal. Outras variáveis que não foram consideradas aqui, como as questões inerentes ao resgate da memória, por exemplo, ao contar eventos estressantes, também poderiam esclarecer e enriquecer estudos sobre a terceira idade.

\section{LIFE EVENTS AND COPING STRATEGIES OF SOCIALLY ACTIVE ELDERLY}

\section{Abstract}

The present study aimed to verify the stressful events of a socially active elderly sample $(\mathrm{N}=40 ; \mathrm{M}=70,40$ years; $\mathrm{sd}=6,24)$, as well as to identify the kind of coping strategies used in order to deal with negative events associated to life in general. For that, in such a way, a half-structuralized interview was used and later on submitted to the content analysis. Data pointed out that the general negative events were mainly related to disease, death and losses. The predominant strategy to cope with situations of life was "Direct Action". It can be considered that these aged ones had used their previous repertoire acquired with their experience of life to use strategies adapted for the action. These results are possibly linked to the factors that influence the well-succeeded aging found in literature, since the participants were socially active.

Keywords: Elders. Life Events. Coping Strategies.

\section{REFERÊNCIAS}

ALDWIN, Carolyn. Stress, Coping and Development: an integrative perspective. New York: Guilford Press, 1994. 
ANTONIAZZI, Adriane Scomazzon; DELL'AGLIO, Débora Dalbosco; BANDEIRA, Denise Ruschel. O Conceito de Coping: uma revisão teórica. Estudos de Psicologia, Natal, v. 3, n. 2, p. 273-294, jul./dez. 1998.

ARGIMON, Irani. Desenvolvimento Cognitivo na Terceira Idade. 2002. $134 \mathrm{f}$. Tese (Doutorado em Psicologia)-Faculdade de Psicologia, Pontifícia Universidade Católica do Rio Grande do Sul, Porto Alegre, 2002.

BALTES, Paul B. Theorethical Propositions of Life-span and Developmental Psychology: on the dynamics, between growth and decline. Developmental Psychology, Washington, DC, v. 23, n. 5, p. 611-696, Sep. 1987.

BARDIN, Laurence. Análise de Conteúdo. Lisboa: Edições 70, 1977.

BECKETT, Megan et al. Social Environment, Life Challenge and Health Among the Elderly in Taiwan. Social Science and Medicine, New York, v. 55, n. 2, p. 191-209, 2002.

BEE, Helen. O Ciclo Vital. Porto Alegre: Artes Médicas Sul, 1997.

BERESFORD, Bryony A. Resources and Strategies: how parents cope with the care of a disabled child. Journal of Child Psychology and Psychiatry, London, v. 35, p. 171-209, Jan. 1994.

BRASIL. Conselho Federal de Psicologia. Resolução CFP n. 16, de 20 de dezembro de 2000. Dispõe sobre a realização de pesquisa em Psicologia com seres humanos. Disponível em: <http://www.pol.org.br/legislacao/doc/resolucao2000_16.doc>. Acesso em: 12 dez. 2005.

BRASIL. Conselho Nacional de Saúde. Resolução 196, de 10 de outubro de 1996. Aprova as diretrizes e normas regulamentadoras de pesquisas envolvendo seres humanos. Disponível em: <http://conselho.saúde.gov.br/docs/Reso196.doc>. Acesso em: 20 jan. 2008.

CACHIONI, Meire. Envelhecimento Bem-Sucedido e Participação numa Universidade para a Terceira Idade: a experiência dos alunos da Universidade São Francisco. 1998. 104 f. Dissertação (Mestrado em Educação)-Faculdade de Edu- 
cação, Universidade Estadual de Campinas, Campinas, 1998.

DELL'AGLIO, Débora Dalbosco. O Processo de Coping, Institucionalização e Eventos de Vida em Crianças e Adolescentes. 2000. 118 f. Tese. (Doutorado em Psicologia)-Instituto de Psicologia, Universidade Federal do Rio Grande do Sul, Porto Alegre, 2000.

FOLKMAN, Susan. Posititive Psychological States and Coping with Severe Stress. Social Science and Medicine, New York, v. 45, p. 1207-1221, 1997.

FORTES, Andréa Cristina Garofe. Eventos de Vida Estressantes, Estratégias de Enfrentamento, Senso de Auto-Eficácia e Estados Depressivos em Idosos Residentes na Comunidade: dados do PENSA. 2005. 153 f. Dissertação (Mestrado)-Faculdade de Educação, Universidade Estadual de Campinas, Campinas, 2005.

FORTES, Andréa Cristina Garofe; NERI, Anita Liberalesso. Eventos de Vida e Envelhecimento Humano. In: YASSUDA, Mônica Sanches; NERI, Anita Liberalesso; CACHIONI, Meire (Org.). Velhice Bem-Sucedida: aspectos afetivos e cognitivos. Campinas: Papirus, 2004. P. 51-70.

HAMARAT, Errol et al. Age Differences in Coping Resources and Satisfaction With Life Among Middle-Aged, Young-Old and Oldest-Old Adults. Journal of Genetic-Psychology, Washington, DC, v. 163, n. 3, p. 360-367, 2002.

HEADEY, Bruce; WEARING, Alexander. Subjective Well-Being and Coping with Adversity. Social Indicators Research, New York, v. 22, p. 327-349, 1989.

KROEFF, Lacimara Ramos. O Idoso e o Seu Processo Grupal, Institucional, num Programa para Idosos. Estudos Interdisciplinares Sobre o Envelhecimento, Porto Alegre, v. 3, p. 103-121, 2001.

LAZARUS, Richard; FOLKMAN, Susan. Stress, Appraisal, and Coping. New York: Springer, 1984.

MC CRAE, Robert. R.; COSTA, Paul. T. Personality, Coping and Coping Effectiveness in an Adult Sample. Journal of Personality, Farmington,v. 54, p. 385-405, 1986 
MORAES, João Feliz Duarte de; SOUZA, Valdemarina Bidone de Azevedo e. Fatores Associados ao Envelhecimento Bem-Sucedido de Idosos Socialmente Ativos da Região Metropolitana de Porto Alegre. Revista Brasileira de Psiquiatria, São Paulo, v. 27, n. 4, p. 302-308, 2005.

NERI, Anita Liberalesso. Desenvolvimento e Envelhecimento: perspectivas biológicas, psicológicas e sociológicas. Campinas: Papirus, 2001.

NERI, Anita Liberalesso. Qualidade de Vida e Idade Madura. Campinas: Papirus, 1993.

PAPALIA, Diane; OLDS, Sally Wendkos. Desenvolvimento Humano. 7. ed. Porto Alegre: Artes Médicas Sul, 2000.

RABELO, Dóris Firmino; NERI, Anita Liberalesso. Recursos Psicológicos e Ajustamento Pessoal Frente à Incapacidade Funcional na Velhice. Psicologia em Estudo, Maringá, v. 10, n. 3, p. 403-412, set./dez. 2005.

RAEDT, Rudi de.; PONJAERT, Kristoffersen, I. Self-Serving Appraisal as a Cognitive Coping Strategy to deal with Age-Related Limitations: an empirical study with elderly adults in a real-life stressful situation. Aging and Mental Health, London, v. 10, n. 2, p. 195-203, 2006.

ROKACH, Ami; AGE NETO, Félix. Age Culture and Coping with Loneliness. Psychology and Education: an interdisciplinary journal, South Carolina, v. 43, n. 2, p. 1-21, 2006.

SANTOS JÚNIOR, Aldemar Ribeiro dos. Política de Atenção à Saúde do Idoso no Distrito Federal: proposta e ação: uma análise bioética. 2005. 116 f. Dissertação (Mestrado em Ciências da Saúde), Universidade de Brasília, Brasília, DF, 2005.

SEIDL, Eliane Maria Fleury; TROCCOLI, Bartholomeu T.; ZANNON, Célia Maria Lana da. Análise Fatorial de uma Medida de Estratégias de Enfrentamento. Psicologia Teoria e Pesquisa, Brasília, DF, v. 17, n. 3, p. 225-234, set./dez. 2001. 
SILVA, Iolete Ribeiro da; GÜINTER, Isolda de Araujo. Papéis Sociais e Envelhecimento em uma Perspectiva de Curso de Vida. Psicologia: teoria e pesquisa, Brasília, DF, v. 16, n. 1, p. 31-40, jan./abr. 2000.

SKINNER, Ellen. A. Perceived Control, Motivation and Coping. London: Sage, 1995.

YASSUDA, Mônica Sanches; NERI, Anita Liberalesso; CACHIONI, Meire (Org.). Velhice Bem-Sucedida: aspectos afetivos e cognitivos. Campinas: Papirus, 2004.

Recebido em: 01/08/2007

$1^{a}$ revisão: $27 / 11 / 2007$

Aceite final: 06/03/2008 